\title{
Rmg8, a New Gene for Resistance to Triticum Isolates of Pyricularia oryzae in Hexaploid Wheat
}

\author{
Vu Lan Anh, Nguyen Tuan Anh, Analiza Grubanzo Tagle, Trinh Thi Phuong Vy, Yoshihiro Inoue, Shigeo Takumi, \\ Izumi Chuma, and Yukio Tosa
}

Graduate School of Agricultural Sciences, Kobe University, Kobe 657-8501, Japan.

Accepted for publication 5 August 2015.

\begin{abstract}
Anh, V. L., Anh, N. T., Tagle, A. G., Vy, T. T. P., Inoue, Y., Takumi, S., Chuma, I., and Tosa, Y. 2015. Rmg8, a new gene for resistance to Triticum isolates of Pyricularia oryzae in hexaploid wheat. Phytopathology 105: 1568-1572.

Blast, caused by Pyricularia oryzae, is one of the major diseases of wheat in South America. We identified a new gene for resistance to Triticum isolates of $P$. oryzae in common wheat 'S-615', and designated it "resistance to Magnaporthe grisea 8" (Rmg8). Rmg8 was assigned to

chromosome $2 \mathrm{~B}$ through molecular mapping with simple-sequence repeat markers. To identify an avirulence gene corresponding to Rmg8, Triticum isolate $\mathrm{Br} 48$ (avirulent on S-615) was crossed with 200R29 (virulent on S-615), an $\mathrm{F}_{1}$ progeny derived from a cross between an Eleusine isolate (MZ5-1-6) and Br48. Segregation analysis of their progeny revealed that avirulence of $\mathrm{Br} 48$ on $\mathrm{S}-615$ was conditioned by a single gene, which was designated AVR-Rmg8. AVR-Rmg8 was closely linked to AVR-Rmg7, which corresponded to $R m g 7$ located on chromosome $2 \mathrm{~A}$ of tetraploid wheat.
\end{abstract}

Development of resistant cultivars carrying resistance $(R)$ genes is the most effective and economical way to control disease. Historically, however, many $R$ genes have been rendered ineffective only a few years after their use in farmers' fields, resulting in a "breakdown of resistance", because of the high pathogenic variability of pathogens (Kiyosawa 1982; Leach et al. 2001). To prevent such breakdowns, cultivars with durable $R$ genes are required.

Pyricularia oryzae, a blast fungus of gramineous plants, is composed of several genus-specific subgroups or pathotypes (Kato et al. 2000), such as the Oryzae isolates pathogenic on rice (Oryzae sativa), Setaria isolates pathogenic on foxtail millet (Setaria italica), Eleusine isolates pathogenic on finger millet, and Triticum isolates pathogenic on wheat (Triticum aestivum). Wheat blast caused by Triticum isolates (Urashima et al. 1993) significantly reduces wheat yields and grain quality; yield losses reach to 70 to $100 \%$ when favorable climatic conditions occur at the critical developmental stages for infection (Cruz et al. 2012; Kohli et al. 2011). The first epidemic of this disease occurred in Paraná State, southern Brazil in 1985 (Igarashi et al. 1986). Since then, it has become widely distributed across most of the wheat-producing areas in Brazil, Argentina, Paraguay, and Bolivia (Cruz et al. 2012; Kohli et al. 2011) because of a lack of resistant cultivars and effective fungicides (Maciel et al. 2014). Recently, wheat blast was also found in North America. In May 2011, P. oryzae was isolated from a single severely blasted wheat head at a research plot at the University of Kentucky Research and Education Center in Princeton. This infection was possibly caused by a host jump from an annual ryegrass pathogen (Pratt 2012). Although no serious outbreaks have been reported outside of South America, there is an increasing threat of wheat blast epidemics in other parts of the world (Kohli et al. 2011).

Corresponding author: Y. Tosa; E-mail address: tosayuki@kobe-u.ac.jp

*The $\boldsymbol{e}$-Xtra logo stands for "electronic extra" and indicates that one supplementary table is published online.

http://dx.doi.org/10.1094/PHYTO-02-15-0034-R

(c) 2015 The American Phytopathological Society
To date, seven blast $R$ genes have been identified in wheat. The first $R$ gene, designated Rmgl (Rwt4), was effective against an Avena isolate but not against Triticum isolates (Takabayashi et al. 2002). Rmg4 and Rmg5 conditioned resistance to a Digitaria isolate but not to Triticum isolates (Nga et al. 2009). Rmg6 was effective against a Lolium isolate but not against Triticum isolates (Vy et al. 2014). These four $R$ genes governed resistance to inappropriate subgroups. On the other hand, the other three genes were effective against isolates of an appropriate subgroup (Triticum isolates), including $R m g 2$ and $R m g 3$, identified in common wheat 'Thatcher' (Zhan et al. 2008), and Rmg7, identified in tetraploid accessions, St24, St17, and St25 (Tagle et al. 2015). These genes may be useful for wheat breeding but have not yet been mapped.

In the present study, we identified a novel gene for resistance to Triticum isolate $\mathrm{Br} 48$ on chromosome $2 \mathrm{~B}$ of hexaploid wheat 'S-615' (S615) and designated it "resistance to Magnaporthe grisea 8" (Rmg8). We also identified its corresponding avirulence $(A V R)$ gene by using progeny derived from a cross between $\mathrm{Br} 48$ and laboratory strain $200 \mathrm{R} 29$.

\section{MATERIALS AND METHODS}

Fungal materials. Isolates used for a preliminary screening were 14 Triticum isolates collected in Brazil in 1990 to 1992 (Supplementary Table S1). After screening, a representative Triticum isolate, $\mathrm{Br} 48$, was used for segregation analyses of wheat $\mathrm{F}_{2}$ and $\mathrm{F}_{3}$ populations. To identify an $A V R$ gene, $\mathrm{Br} 48(M A T 1-1)$ was crossed with 200R29 (MAT1-2), a highly virulent $\mathrm{F}_{1}$ culture derived from a cross between Eleusine isolate MZ5-1-6 and Br48 (Tagle et al. 2015), as described previously (Murakami et al. 2000). A random hybrid population was produced by sampling one ascospore from each ascus. These cultures were maintained on barley seed media, as described previously (Hirata et al. 2007).

Plant materials. Plant materials used for the preliminary screening were 31 cultivars of common wheat (T. aestivum L.) provided by Dr. K. Tsunewaki, formerly of Kyoto University, and Dr. U. Hiura, formerly of Okayama University. After the screening, three representative cultivars were selected for further analyses. 
Common wheat $\mathrm{S} 615$ was resistant to Br48, whereas 'Shin-chunaga' (Sch) and 'Hope' were susceptible (Table 1). Tetraploid accession T. dicoccum KU-120 (St24) was employed for a comparison of $R$ genes because it carried $R m g 7$ (Tagle et al. 2015). Wheat seed were pregerminated by incubation on moistened filter papers at $22^{\circ} \mathrm{C}$ for $24 \mathrm{~h}$, sown in vermiculite supplied with liquid fertilizer in a seedling case $\left(5.5\right.$ by 15 by $10 \mathrm{~cm}$ ), and grown at $22^{\circ} \mathrm{C}$ in a controlled-environment room with a 12 -h photoperiod of fluorescent lighting for 7 days. Leaves were then fixed onto a hard plastic board for inoculation.

Infection assays. Inocula were prepared following the protocol described by Tagle et al. (2015). The inoculum suspension $\left(1 \times 10^{5}\right.$ conidia/ml) was sprayed onto adaxial surfaces of the 7-day-old primary leaves using an air compressor. The inoculated plants were incubated for $24 \mathrm{~h}$ in darkness in humid trays at 22 or $25^{\circ} \mathrm{C}$, after which they were transferred to dry conditions under fluorescent lighting and further incubated at the same temperature. Disease symptoms were evaluated 4 or 5 days after inoculation based on the color of lesions and the affected leaf area. The affected area was rated by six progressive grades from 0 to 5 , where $0=$ no visible evidence of infection, $1=$ pinhead spots, $2=$ small lesions $(<1.5 \mathrm{~mm}), 3=$ scattered lesions of intermediate size $(<3 \mathrm{~mm}), 4=$ large typical lesions, and $5=$ complete blighting of leaf blades. A disease score is composed of a number denoting the size of lesions and a letter or letters indicating the lesion color: " $\mathrm{B}$ " for brown and "G" for green. Infection types with brown lesions were considered to be resistant or avirulent while those with infection types $3 \mathrm{G}, 4 \mathrm{G}$, and $5 \mathrm{G}$ were taken as susceptible or virulent. Sometimes lesions of size 3 and 4 were accompanied by both brown and green tissue. These types, designed as 3BG and 4BG, were considered moderately resistant or moderately avirulent (Hyon et al. 2012). All infection assays at the seedling stage were repeated at least three times.

For infection assays of wheat plants at the heading stage, stems with spikes at the stage of full head emergence were cut from wheat
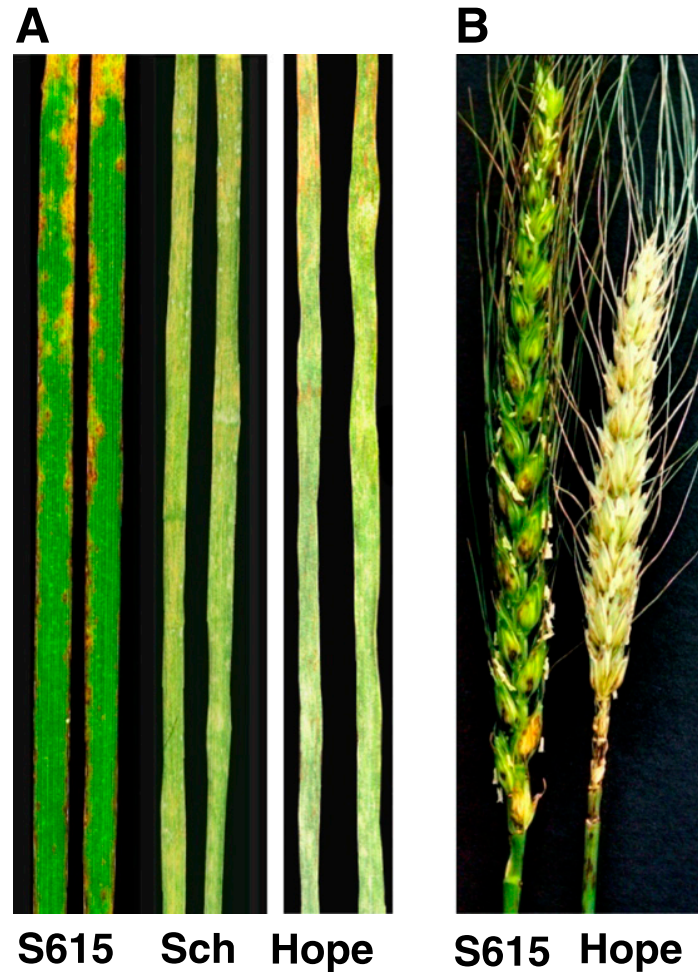

Fig. 1. Symptoms on A, seedlings and B, spikes of resistant 'S615' and susceptible 'Shin-chunaga' (Sch) or 'Hope', 5 days after inoculation with Triticum isolate $\mathrm{Br} 48$ at $25^{\circ} \mathrm{C}$. plants that had been sown in an experimental field in the autumn of the previous year, and put in flasks with water. Spikes of the susceptible cultivar ( $\mathrm{Sch}$ ) could not be harvested simultaneously with the resistant cultivar (S615) because of different heading times; Sch was early heading while S615 was late heading. Therefore, lateheading Hope was used as a susceptible control for assays at the heading stage. Harvested spikes were inoculated with conidial suspensions $\left(1 \times 10^{5}\right.$ spores $\left./ \mathrm{ml}\right)$, covered with a plastic bag, and placed in darkness at $25^{\circ} \mathrm{C}$ for $24 \mathrm{~h}$. The plastic bag was removed and the set-up was incubated further at the same temperature with $12 \mathrm{~h}$ each of alternate light and dark conditions. Five days after inoculation, spike infections were rated with six progressive grades from 0 to 5 , where $0=$ no visible evidence of infection, $1=$ pinhead spots, $2=$ small lesions $(<1.5 \mathrm{~mm}), 3=$ scattered lesions of intermediate size $(<3 \mathrm{~mm}), 4=$ mixture of green and white tissues with no apparent browning caused by hypersensitive reaction, and $5=$ complete blighting of the spike. Infection types 0 to 3 were considered resistant and 4 to 5 were susceptible. Three spikes were used for each wheat cultivar per replication. All infection assays at the heading stage were repeated twice.

Molecular mapping. To map Rmg 8 and $R m g 7,93 \mathrm{~F}_{2}$ plants derived from a cross between $\mathrm{S} 615$ and $\mathrm{Sch}$ and $94 \mathrm{~F}_{2}$ plant derived from a cross between St24 and Tat14 (T. paleocolchicum KU-156, highly susceptible to $\mathrm{Br} 48$ ) (Tagle et al. 2015) were grown in a field and selfed. From each of the resulting $\mathrm{F}_{3}$ lines, 20 seeds were used for disease assays with $\mathrm{Br} 48$. Another 20 seeds were grown at $22^{\circ} \mathrm{C}$ for 5 to 7 days, and pooled leaf tissue samples were used for DNA extraction.

Based on phenotypic data, five homozygous resistant $(R R)$ and five homozygous susceptible $(r r) \mathrm{F}_{3}$ lines were selected for bulked segregant analysis (Michelmore et al. 1991). Resistant and susceptible bulks $(10 \mathrm{ng} / \mu \mathrm{l})$ were constructed by mixing equal amounts of DNA of the five $R R$ and five $r r \mathrm{~F}_{3}$ lines, respectively. Simple-sequence repeat (SSR) loci reported by Somers et al. (2004) and Torada et al. (2006) were amplified from DNA of the parental cultivars and the two bulks. Polymerase chain reaction (PCR) products were separated in $2 \%$ agarose or in $13 \%$ nondenaturing polyacrylamide gels using a high-efficiency genome scanning system (Nippon Eido, Tokyo) (Hori et al. 2003). Markers showing a possibility of linkage were then subjected to analyses on the $\mathrm{F}_{3}$ lines to construct a linkage map. A genetic map was constructed using software MAPMARKER (Lander et al. 1987). Thresholds of linkage for map construction were a minimum log-of-likelihood ratio of 4.0 and a maximum recombination fraction of 0.4 . The Kosambi mapping function was employed to compute map distances in centimorgans.

TABLE 1. Infection types of wheat seedlings with Triticum isolate Br48, Eleusine isolate MZ5-1-6, and $\mathrm{F}_{1}$ culture 200R29 derived from the cross MZ5$1-6 \times \mathrm{Br} 48$

\begin{tabular}{|c|c|c|c|c|c|c|c|}
\hline \multirow[b]{3}{*}{ Wheat line } & \multirow[b]{3}{*}{ Lab code } & \multicolumn{6}{|c|}{ Infection type with ${ }^{\mathrm{a}}$} \\
\hline & & \multicolumn{2}{|c|}{$\mathrm{Br} 48$} & \multicolumn{2}{|c|}{ 200R29 } & \multicolumn{2}{|c|}{ MZ5-1-6 } \\
\hline & & $22^{\circ} \mathrm{C}$ & $25^{\circ} \mathrm{C}$ & $22^{\circ} \mathrm{C}$ & $25^{\circ} \mathrm{C}$ & $22^{\circ} \mathrm{C}$ & $25^{\circ} \mathrm{C}$ \\
\hline \multicolumn{8}{|c|}{ Triticum aestivum } \\
\hline 'S-615' & S615 & $0-1 \mathrm{~B} *$ & $1-2 \mathrm{~B}^{*}$ & $3 \mathrm{BG}^{*}$ & $5 \mathrm{G}$ & $1 \mathrm{~B}^{*}$ & $2 \mathrm{~B}^{*}$ \\
\hline T. aestivum, & & & & & & & \\
\hline 'Shin-chunaga' & Sch & $5 \mathrm{G}$ & $5 \mathrm{G}$ & $3-4 G$ & $5 \mathrm{G}$ & $1 \mathrm{~B}^{*}$ & $1 B^{*}$ \\
\hline $\begin{array}{l}\text { T. aestivum } \\
\text { 'Hope' }\end{array}$ & Hope & $5 \mathrm{G}$ & $5 \mathrm{G}$ & $5 \mathrm{G}$ & $5 \mathrm{G}$ & $0-1 \mathrm{~B} *$ & $0^{*}$ \\
\hline T. dicoccum & & & & & & & \\
\hline KU-120 & St24 & $0^{*}$ & $1-2 \mathrm{~B} *$ & $1-2 \mathrm{~B}^{*}$ & $5 \mathrm{G}$ & $1-2 \mathrm{~B} *$ & $5 \mathrm{G}$ \\
\hline
\end{tabular}

a Evaluated 5 days after inoculation, where $0=$ no visible evidence of infection, $1=$ pinhead spots, $2=$ small lesions $(<1.5 \mathrm{~mm}), 3=$ scattered lesions of intermediate size $(<3 \mathrm{~mm}), 4=$ large typical lesions, and $5=$ complete blighting of leaf blades; $\mathrm{B}$ and $\mathrm{G}$ indicate brown and green lesions, respectively. Asterisks indicate resistant reactions. 


\section{RESULTS}

Infection assays at the seedling stage. Screening of the common wheat cultivars revealed that $\mathrm{S} 615$ was resistant to all Triticum isolates at both 22 and $25^{\circ} \mathrm{C}$ while Sch and Hope were susceptible (Table 1; Fig. 1A). Consequently, we selected these three cultivars for further analyses. When an $\mathrm{F}_{2}$ population derived from a cross between S615 and Sch was inoculated with Br48, resistant and susceptible seedlings segregated (Fig. 2) in a 3:1 ratio $\left(164: 42, \chi^{2}=2.34\right)$. In $F_{3}$ populations, nonsegregating resistant, segregating, and nonsegregating susceptible lines were distributed in a 1:2:1 ratio $\left(21: 52: 20, \chi^{2}=1.32\right)$, indicating that the resistance of $\mathrm{S} 615$ to $\mathrm{Br} 48$ was controlled by a single dominant gene. This gene was designated $R m g 8$.

Infection assays at the heading stage. To check whether the resistance of S615 is expressed at the heading stage, its spikes were inoculated with $\mathrm{Br} 48$ together with those of the susceptible control Hope and incubated at $25^{\circ} \mathrm{C}$. The spikes of S615 showed infection type 2, with small brown lesions caused by a hypersensitive reaction (Fig. 1B), as expected. By contrast, the spikes of Hope were completely blighted with infection type 5 (Fig. 1B).

Identification of an $A V R$ gene in a Triticum isolate. In order to identify an $A V R$ gene corresponding to $R m g 8$, an isolate virulent on the $R m g 8$ carrier is required as a mating partner of $\mathrm{Br} 48$. However, S615 was resistant to all Triticum isolates tested. To find a mating partner, S615 was inoculated with isolates from other

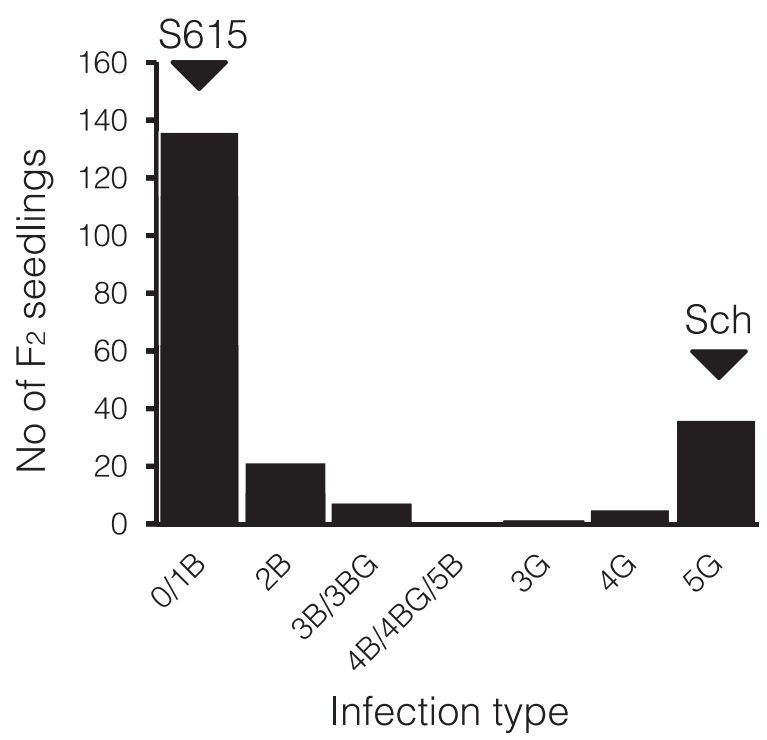

Fig. 2. Frequency distribution of infection types with Triticum isolate $\mathrm{Br} 48$ at $22^{\circ} \mathrm{C}$ in $\mathrm{F}_{2}$ seedlings derived from the cross between S615 and Sch. Infection type $0=$ no visible evidence of infection, $1=$ pinhead spots, $2=$ small lesions $(<1.5 \mathrm{~mm}), 3=$ scattered lesions of intermediate size $(<3 \mathrm{~mm}), 4=$ large typical lesions, and $5=$ complete blighting of leaf blades; $\mathrm{B}$ and $\mathrm{G}$ indicate brown and green lesions, respectively. host-specific subgroups (e.g., Eleusine isolates and Setaria isolates) and their descendants, and incubated at 22 and $25^{\circ} \mathrm{C}$. Several virulent cultures were found in an $\mathrm{F}_{1}$ population derived from MZ51-6 (Eleusine isolate) $\times \mathrm{Br} 48$. Their mating types were checked using MAT1-1- and MAT1-2-specific primers (Zheng et al. 2008). Finally, 200R29 was selected as the mating partner because it carried the MAT1-2 allele and was highly virulent on $\mathrm{S} 615$ at $25^{\circ} \mathrm{C}$ (Table 1). Br48 (MAT1-1) was crossed with 200R29, resulting in 73 random hybrid cultures. When they were sprayed on S615 and incubated at $25^{\circ} \mathrm{C}, 31$ and 40 cultures were stably avirulent and virulent, respectively (Table 2). There were two exceptional cultures whose infection types were unstable (i.e., fluctuated among replications). Regardless of their categorization, however, segregation of avirulent and virulent cultures fitted a 1:1 ratio (Table 2), suggesting that a single gene is involved in the avirulence of $\mathrm{Br} 48$ on S615. This $A V R$ gene was designated AVR-Rmg8.

When the 73 cultures were sprayed onto St 24 carrying $R m g 7$, avirulent and virulent cultures segregated in a 1:1 ratio (Table 2). This gene was considered to be $A V R-R m g 7$, corresponding to $R m g 7$ (Tagle et al. 2015). To check whether $A V R-R m g 8$ and $A V R-R m g 7$ are located at the same locus, the segregation patterns on S615 and St24 were compared. When the unstable two cultures were classified as "virulent", the segregation patterns on S615 and St24 were perfectly concordant (Table 3). When these two cultures were classified as "avirulent", however, they were regarded as recombinants (Table 3).

Molecular mapping of $\boldsymbol{R} \boldsymbol{m g} 8$. To determine the chromosomal position of $R m g 8$, bulked-segregant analysis was performed with the $\mathrm{F}_{3}$ lines derived from a cross between S615 and Sch. Of 725 SSR markers tested, 290 were polymorphic between the parental accessions. Twelve polymorphic markers located on chromosome 2B appeared to be associated with Rmg8 in bulked segregant analysis. Genotyping of all $\mathrm{F}_{3}$ lines indicated that $R m g 8$ was flanked by SSR markers Xwmc317 and Xbarc159 (Fig. 3), assigned to the distal region in the long arm of chromosome $2 \mathrm{~B}$ (Somers et al. 2004).

To determine the chromosomal position of $R m g 7,94 \mathrm{~F}_{3}$ lines derived from a cross between St24 (Rmg7) and Tat14 ( $r m g 7$ ) were employed. When they were inoculated with $\mathrm{Br} 48$, nonsegregating resistant, segregating, and nonsegregating susceptible lines were distributed in a $1: 2: 1$ ratio $\left(26: 45: 23, \chi^{2}=0.36\right)$. Molecular mapping with these $\mathrm{F}_{3}$ lines indicated that $R m g 7$ was flanked by SSR markers $X c f d 50$ and $X h b g 327$ (Fig. 3), assigned to the distal region in the long arm of chromosome 2A (Somers et al. 2004).

TABLE 3. Combined segregation of virulence on two wheat lines in a population derived from the cross $\mathrm{Br} 48 \times 200 \mathrm{R} 29$

\begin{tabular}{lccccc}
\hline $\begin{array}{l}\text { Categorization } \\
\text { of unstable } \\
\text { cultures }\end{array}$ & \multicolumn{5}{c}{ Number of cultures $^{\mathrm{a}}$} \\
\cline { 2 - 7 } & $\mathrm{A}_{\mathrm{S} 615} \mathrm{~A}_{\mathrm{St24}}{ }^{\mathrm{a}}$ & $\mathrm{A}_{\mathrm{S} 615} \mathrm{~V}_{\mathrm{St} 24}$ & $\mathrm{~V}_{\mathrm{S} 615} \mathrm{~A}_{\mathrm{St} 24}$ & $\mathrm{~V}_{\mathrm{S} 615} \mathrm{~V}_{\mathrm{St} 24}$ & Total \\
\hline Avirulent & 31 & 2 & 0 & 40 & 73 \\
Virulent & 31 & 0 & 0 & 42 & 73 \\
\hline
\end{tabular}

a $\mathrm{A}=$ avirulent and $\mathrm{V}=$ virulent. For example, $\mathrm{A}_{\mathrm{S} 615} \mathrm{~V}_{\mathrm{St} 24}$ represents cultures that are avirulent on S615 and virulent on St24.

TABLE 2. Responses of wheat seedlings to a population derived from the cross, $\mathrm{Br} 48 \times 200 \mathrm{R} 29$

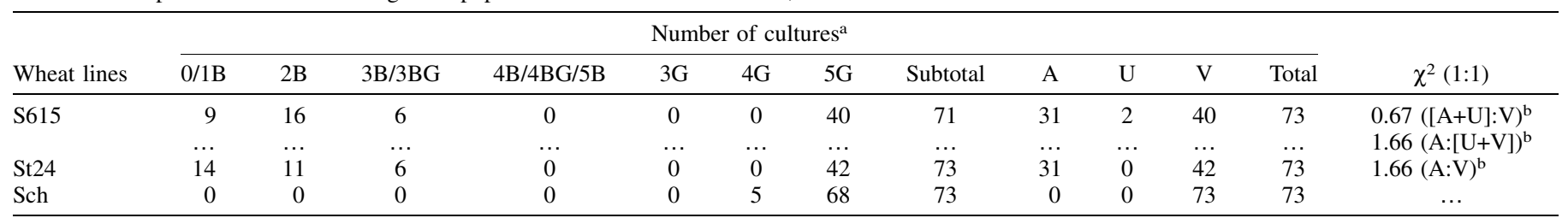

${ }^{a}$ Infection type, 5 days after inoculation at $25^{\circ} \mathrm{C}$, where $0=$ no visible evidence of infection, $1=$ pinhead spots, $2=$ small lesions $(<1.5 \mathrm{~mm}), 3=$ scattered lesions of intermediate size $(<3 \mathrm{~mm}), 4=$ large typical lesions, and $5=$ complete blighting of leaf blades; $\mathrm{B}$ and $\mathrm{G}$ indicate brown and green lesions, respectively; A = avirulent (infection type 0 to $3 \mathrm{BG}$ ), $\mathrm{U}=$ unstable (fluctuate from $4 \mathrm{~B} / 4 \mathrm{BG}$ to $4 \mathrm{G}$ ), and $\mathrm{V}=$ virulent (infection type $3 \mathrm{G}$ to $5 \mathrm{G}$ ).

b Not significant at $P=0.05$. 


\section{DISCUSSION}

In the present study, we identified $\operatorname{Rmg} 8$, a dominant gene conferring strong resistance to Triticum isolate $\mathrm{Br} 48$ in common wheat S615. This gene was located on the long arm of chromosome 2B (Fig. 3). Rmg8 should be different from Rmg2 and Rmg3, two of the three $R$ genes previously identified as effective against Triticum isolates, because $R m g 2$ and $R m g 3$ are located on chromosomes 7A and 6B, respectively (Zhan et al. 2008). $\operatorname{Rmg} 8$ also should be different from the other (third) $R$ gene, $R m g 7$, which was identified in a tetraploid wheat accession (St24) by Tagle et al. (2015), because Rmg7 is located on chromosome 2A (Fig. 3).

Segregation analysis of a fungal hybrid population suggested that their corresponding $A V R$ genes, $A V R-R m g 7$ and $A V R-R m g 8$, are closely linked or located at the same locus (Table 3). If these $A V R$ genes are the same, this means that a single $A V R$ gene corresponds to $R m g 7$ in tetraploid wheat and $R m g 8$ in hexaploid wheat. It should be noted that $R m g 8$ and $R m g 7$ are located in the distal regions of long arms of homeologous chromosomes $2 \mathrm{~B}$ and 2A, respectively (Fig. 3). There is a possibility that $R m g 8$ in hexaploid wheat and $R m g 7$ in tetraploid wheat are homeologous genes. To verify the homeologous relationship between $R m g 8$ and $R m g$ 7, fine mapping of these genes should be performed in further studies.

$R$ genes to be used in breeding for resistance to wheat blast must fulfill some requirements. First, they must be expressed at the heading stage because wheat blast in the field is primarily a spike disease. Variation in blast response among wheat cultivars has been recognized at both the seedling and adult plant stages (Cruz et al. 2012; Prestes et al. 2007; Urashima et al. 2004). Cruz et al. (2012) suggested that seedling infection assays were not reliable in predicting the severity of spike infection. Maciel et al. (2014) showed that there was not a strong correlation between seedling and spike reactions to the wheat blast pathogen. On the other hand, Tagle et al. (2015) showed that tetraploid accessions carrying Rmg7 (St17,

Chr. 2B

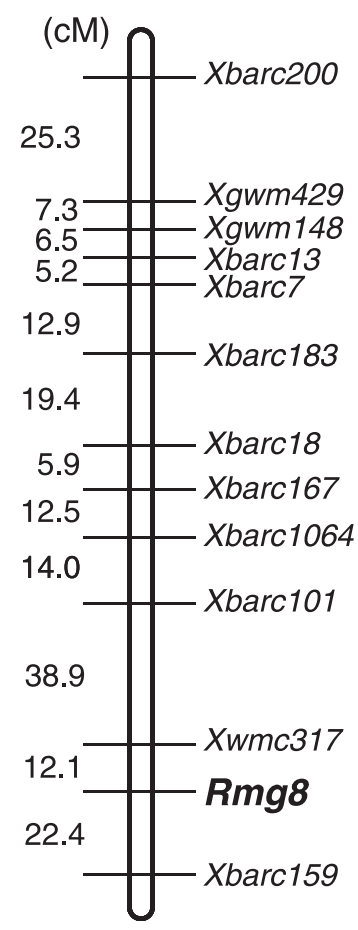

Fig. 3. Genetic map of the $R m g 8$ (left) and $R m g 7$ (right) regions constructed using $F_{3}$ lines derived from crosses between two common wheat cultivars (S615 and Sch) and two tetraploid wheat accessions (St24 and Tat14), respectively; $\mathrm{cM}=$ centimorgans.
St24, and St25) were highly resistant even at the heading stage. In the present study, we found that S615 carrying Rmg8 conferred resistance not only at the seedling stage but also at the heading stage. If resistance at the heading stage is conferred by $R m g 8$, then it is considered to fulfill the first requirement.

Second, $R$ genes must be durable. The durability of $R$ genes may be predicted by evaluating a fitness cost imposed by mutation of or constraints imposed on corresponding $A V R$ genes (Janzac et al. 2009; Leach et al. 2001; Vera Cruz et al. 2000), or by estimating the stability of corresponding $A V R$ genes based on their chromosomal location and the molecular structure around them (Chuma et al. 2011; Tosa and Chuma 2014). In any case, identification of $A V R$ genes is a prerequisite to evaluate durability of new $R$ genes. To identify an $A V R$ gene corresponding to an $R$ gene $(R l)$, we need an isolate virulent on $R l$. However, this requirement includes an intrinsic antinomy; durable $R$ genes should be resistant to all prevailing Triticum isolates. In this respect, $R m g 7$ and $R m g 8$ were effective against all Triticum isolates tested. Tagle et al. (2015) solved this problem by using temperature sensitivity of avirulence of an Eleusine isolate on the $R m g 7$ carriers. In the present study, we overcame this problem by producing a culture virulent on $\operatorname{Rmg} 8$ (200R29) through crossing a Triticum isolate $(\mathrm{Br} 48)$ with an Eleusine isolate (MZ5-1-6). By backcrossing this virulent isolate with the Triticum isolate, we successfully identified $A V R-R m g 8$. Cloning of $A V R-R m g 8$ is under way to reveal its chromosomal location, surrounding molecular structure, and the fitness cost imposed by its mutations.

\section{ACKNOWLEDGMENTS}

We thank Emeritus Professors K. Tsunewaki and S. Sakamoto, Kyoto University, for providing seed of the wheat lines; M. Terada, Kobe University, for crossing the isolates; and Dr. R. McIntosh, University of Sydney, for critical reading and editing of the manuscript.

\section{LITERATURE CITED}

Chuma, I., Isobe, C., Hotta, Y., Ibaragi, K., Futamata, N., Kusaba, M., Yoshida, K., Terauchi, R., Fujita, Y., Nakayashiki, H., Valent, B., and Tosa, Y. 2011. Multiple translocation of the AVR-Pita effector gene among chromosomes of the rice blast fungus Magnaporthe oryzae and related species. PLoS Pathog. 7:e1002147.

Cruz, C. D., Bockus, W. W., Stack, J. P., Tang, X., Valent, B., Pedley, K. F., and Peterson, G. L. 2012. Preliminary assessment of resistance among U.S. wheat cultivars to the Triticum pathotype of Magnaporthe oryzae. Plant Dis. 96:1501-1505.

Hirata, K., Kusaba, M., Chuma, I., Osue, J., Nakayashiki, H., Mayama, S., and Tosa, Y. 2007. Speciation in Pyricularia inferred from multilocus phylogenetic analysis. Mycol. Res. 111:799-808.

Hori, K., Kobayashi, T., Shimizu, A., Sato, K., and Kawasaki, S. 2003. Efficient construction of high-density linkage map and its application to QTL analysis in barley. Theor. Appl. Genet. 107:806-813.

Hyon, G.-S., Nga, N. T. T., Chuma, I., Inoue, Y., Asano, H., Murata, N., Kusaba, M., and Tosa, Y. 2012. Characterization of interactions between barley and various host-specific subgroups of Magnaporthe oryzae and M. grisea. J. Gen. Plant Pathol. 78:237-246.

Igarashi, S., Utimada, C. M., Igarashi, L. C., Kazuma, A. H., and Lopes, R. C. 1986. Pyricularia sp. em trigo. I. Ocorrência de Pyricularia sp. no estado do Paraná. Fitopatol. Bras. 11:351-352.

Janzac, B., Fabre, F., Paloix, A., and Moury, B. 2009. Constraints on evolution of virus avirulence factors predict the durability of corresponding plant resistances. Mol. Plant Pathol. 10:599-610.

Kato, H., Yamamoto, M., Yamaguchi-Ozaki, T., Kadouchi, H., Iwamoto, Y., Nakayashiki, H., Tosa, Y., Mayama, S., and Mori, N. 2000. Pathogenicity, mating ability and DNA restriction fragment length polymorphisms of Pyricularia populations isolated from Gramineae, Bambusideae and Zingiberaceae plants. J. Gen. Plant Pathol. 66:30-47.

Kiyosawa, S. 1982. Genetics and epidemiological modeling of breakdown of plant disease resistance. Annu. Rev. Phytopathol. 20:93-117.

Kohli, M. M., Mehta, Y. R., Guzman, E., de Viedma, L., and Cubilla, L. E. 2011. Pyricularia blast-A threat to wheat cultivation. Czech. J. Genet. Plant Breed. 47:S130-S134. 
Lander, E. S., Green, P., Abrahamson, J., Barlow, A., Daley, M. J., Lincoln, S. E., and Newberg, L. A. 1987. MAPMAKER: An interactive computer package for constructing primary genetic linkage maps of experimental and natural populations. Genomics 1:174-181.

Leach, J. E., Vera Cruz, C. M., Bai, J., and Leung, H. 2001. Pathogen fitness penalty as a predictor of durability of disease resistance genes. Annu. Rev. Phytopathol. 39:187-224.

Maciel, J. L. N., Ceresini, P. C., Castroagudin, V. L., Zala, M., Kema, G. H. J., and McDonald, B. A. 2014. Population structure and pathotype diversity of the wheat blast pathogen Magnaporthe oryzae 25 years after its emergence in Brazil. Phytopathology 104:95-107.

Michelmore, R. W., Paran, I., and Kesselin, R. V. 1991. Identification of markers linked to disease-resistance genes by bulked segregant analysis: A rapid method to detect markers in specific genomic regions by using segregating populations. Proc. Natl. Acad. Sci. USA 88:9828-9832.

Murakami, J., Tosa, Y., Kataoka, T., Tomita, R., Kawasaki, J., Chuma, I., Sesumi, Y., Kusaba, M., Nakayashiki, H., and Mayama, S. 2000. Analysis of host species specificity of Magnaporthe grisea toward wheat using a genetic cross between isolates from wheat and foxtail millet. Phytopathology 90:1060-1067.

Nga, N. T. T., Hau, V. T. B., and Tosa, Y. 2009. Identification of genes for resistance to a Digitaria isolate of Magnaporthe grisea in common wheat cultivars. Genome 52:801-809.

Pratt, K. 2012. UK researchers find important new disease. In: UK College of Agriculture News. Online publication. College of Agriculture, University of Kentucky. http://news.ca.uky.edu/article/uk-researchers-find-important-new-disease

Prestes, A. M., Arendt, P. F., Fernandes, J. M. C., and Scheeren, P. L. 2007. Resistance to Magnaporthe grisea among Brazilian wheat genotypes. Pages 119-123 in: Wheat Production in Stressed Environments. H. T. Buck, J. E. Nisi, and N. Salomón, eds. Springer, Dordrecht, The Netherlands.

Somers, D. J., Isaac, P., and Edwards, K. 2004. A high-density microsatellite consensus map for bread wheat (Triticum aestivum L.). Theor. Appl. Genet. 109:1105-1114.
Tagle, A. G., Chuma, I., and Tosa, Y. 2015. Rmg7, a new gene for resistance to Triticum isolates of Pyricularia oryzae identified in tetraploid wheat. Phytopathology 105:495-499.

Takabayashi, N., Tosa, Y., Oh, H. S., and Mayama, S. 2002. A gene-for-gene relationship underlying the species-specific parasitism of Avena/Triticum isolates of Magnaporthe grisea on wheat cultivars. Phytopathology 92: 1182-1188.

Torada, A., Koike, M., Mochida, K., and Ogihara, Y. 2006. SSR-based linkage map with new markers using an intraspecific population of common wheat. Theor. Appl. Genet. 112:1042-1051.

Tosa, Y., and Chuma, I. 2014. Classification and parasitic specialization of blast fungi. J. Gen. Plant Pathol. 80:202-209.

Urashima, A. S., Igarashi, S., and Kato, H. 1993. Host range, mating type and fertility of Pyricularia grisea from wheat in Brazil. Plant Dis. 77: 1211-1216.

Urashima, A. S., Lavorent, N. A., Goulart, A. C. P., and Mehta, R. 2004. Resistance spectra of wheat cultivars and virulence diversity of Magnaporthe grisea isolates in Brazil. Fitopatol. Bras. 29:511-518.

Vera Cruz, C. M., Bai, J., Oña, I., Leung, H., Nelson, R. J., Mew, T.-W., and Leach, J. E. 2000. Predicting durability of a disease resistance gene based on an assessment of the fitness loss and epidemiological consequences of avirulence gene mutation. Proc. Natl. Acad. Sci. USA 97: 13500-13505

Vy, T. T. P., Hyon, G., Nga, N. T. T., Inoue, Y., Chuma, I., and Tosa, Y. 2014. Genetic analysis of host-pathogen incompatibility between Lolium isolates of Pyricularia oryzae and wheat. J. Gen. Plant Pathol. 80:59-65.

Zhan, S. W., Mayama, S., and Tosa, Y. 2008. Identification of two genes for resistance to Triticum isolates of Magnaporthe oryzae in wheat. Genome 51:216-221.

Zheng, Y., Zhang, G., Lin, F., Wang, Z., Jin, G., Yang, L., Wang, Y., Chen, X., Xu, Z., Zhao, X., Wang, H., Lu, J., Lu, G., and Wu, W. 2008. Development of microsatellite markers and construction of genetic map in rice blast pathogen Magnaporthe grisea. Fungal Genet. Biol. 45:1340-1347. 